\title{
Comparative Analysis of Development Program of Concepts and Categories Through Cognitive Perceptive Networks in Students with Autism Spectrum Disorder
}

\author{
Manuel Ojea Rúa* \\ Department of Psycho-Pedagogy, University of Vigo, Spain

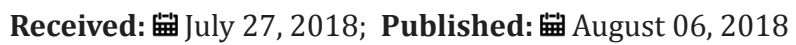 \\ *Corresponding author: Manuel Ojea Rúa, Department of Psycho-Pedagogy, University of Vigo, Spain
}

\begin{abstract}
Individuals with autism spectrum disorder (ASD) exhibit social- communicative impairments, which cognitive and neuropsychological deficits are evident. This research study presents an experimental study to prove effectiveness of a psychologic program, designed to facilitate conceptual and categorical development through learning of links between concepts. A total of 27 students with ASD participated in study, evaluated over 9 months, throughout three successive measures, distributed in two groups: an experimental group $(n=14)$ and a control group $(n=13)$. Results found through ANOVA comparative analysis and independent samples t- test for equality of means show there're significant differences in the cognitive conceptual development among experimental group participants compared to their peers of control group.
\end{abstract}

Keywords: Autism; Perception; Cognition; Sensory Integration; Semantic Memory

\section{Introduction}

According to International Classification of Mental Disorders of American Psychiatric Association [1], people with autism spectrum disorder (ASD) show a characteristic perceptual processing, which also extends to evaluation of experience, both external and internal, since processes of analysis are conditioned, both the information coming from environment, as the existing contents in permanent memory. Mevel, Fransson and Bölte (2015) affirm that these deficits are due to complex interaction of genetic and environmental factors, which affect cerebral maturation, synaptic function and cortical networks. [2] deepen into an etiological study and conclude that analysis performed with a comparative genomic hybridization matrix (array-CGH), indicates that copy number variants (CNV) are associated with the susceptibility of people with ASD, which is an important specificity of these individuals. Likewise, [3] points out that cognitive processing follows a sequence in which, neuronal system determines strength of signals detected, so process transforms initial visual stimulus into neuronal impulses, which are transformed from retina to the brain in many ways, of which, the most remarkable is the lateral geniculate nucleus. Then, arrive to primary visual cortex, where it occurs analysis process of individual features observed of initial stimulus. From this moment, it's distributed to several areas, that process the isolated features, which are combined in multiple ways to configure a global representation of initial image of retina. But, there hasn't yet been conceptual- categorial attribution, thus, still must go to an intermediate and superior perceptual level, where inferior temporal cortex will develop an essential performance, so any deficit on any area of lower temporal cortex can cause deficits to the recognition of perceived object [4] have explored specificity of the activation of facial processing in people with ASD and its results demonstrate a hypoactivation in facial processing system of human faces, but not of animals, possibly due to limitations in ability to represent value of social stimuli [5] say these neurological deficits aren't limited to one or several domains, but in their interaction, exhibiting limited cerebral axes, related with ability to modify attention and executive function, while indicating better potential in activities planning [6].

Deepen into the possible causes of conceptual integration deficits, which's explained by the cognitive hypotheses of coherence and conclude that people with ASD during joint attention processes showed reduced temporal-central alpha coherence in right hemisphere compared to their peers in the typical development group. Then, studies about presence of a local perception are 
corroborated, just as the theory of cognitive central coherence affirms [7]. Likewise, these hypotheses were analyzed by [8], that suggest global integration is reduced, being an important factor of weak central coherence. Whereby, executive system is affected, with great limitations for conceptual integration and categorical hierarchy. In this sense [9], investigate the computational work and suggests these deficits may be result of atypical representations in people with ASD in cortical maps, derived the idiosyncratic perceptual processes observed.

\section{Aims}

Adapted various methodological proposals related to people with ASD to respond to these specific needs [10,11]. However, a recurring theme is existence of an empty in programs design to create links between the concepts; therefore, this research's main aim is to design a specific program to facilitate of conceptual and sensory integration development, through creation of relational links or networks. Thus, basic aims are the following:

A. Design and apply a specific program to facilitate conceptual sensory integration, through creation of perceptivecognitive networks to people with ASD.

B. Evaluate the application of program on the experimental group participants, compared with his peers of control group.

\section{Method}

Design: Research design is supported by an experimental model of two groups, 1 Experimental Group (EG), to which a specific program was applied, and 1 Control Group (CG), whose participants followed the regular programs.

Participants: A total of 27 students with ASD participated in study, of three diagnosis levels, of both sexes and of ages between 4-15 years, which have been divided heterogeneously in both groups: the experimental and control group.

Instruments: Evaluation analysis was developed with the following psychometric tests, operationalized in the variables: "frostig" y "text":

a) "frostig" variable was measured with the Visual Perception Test of "FROSTIG" (Frostig, 2009).

b) "text" variable was evaluated throughout texts adapted to the curricular competence of each participant.

Variables: The variables: "frostig" and "text" for their three evaluation measures were statistically calculated to form a new variable named "networks" for the three measures: "networks1-2-3" (Table 1).

Table 1: Variables name.

\begin{tabular}{|c|c|c|}
\hline Variables name & Statistic calculation & Concept \\
\hline "frostig1-2-3" \& "text1-2-3" & "networks1-2-3" & $\begin{array}{c}\text { Development of networks, links for conceptual- } \\
\text { semantic comprehension, with 3 repeated } \\
\text { measures ("networks1, 2, 3"). }\end{array}$ \\
\hline "Group" & & $\begin{array}{c}\text { Type of group: 1 Experimental Group (EG) and 1 } \\
\text { Control Group (CG). }\end{array}$ \\
\hline
\end{tabular}

Procedure: The authorizations and ethical considerations were requested. Then, participants were distributed proportionally in the experimental group and control group.

Over a period of 9 months 3 successive evaluation measures were carried out to both groups: 1) first measure: "frostig1" y "text1" (experimental group began the application of a specific adapted program, while control group continued the regular programs), 2) after 4,5 months, second measurement was made: "frostig2" and "text2, and 3) finally, 4,5 months later, third measure of comparison between experimental group and control group was assessed: "frostig3" y "text3".

5.6 Data analysis: Results were calculated for the variable: "networks" (1-2-3), in relation to variable "group", through the ANOVA analysis of repeated measures and independent samples ttest for equality of means, of statistical package SPSS, version 23.

\section{Program}

Program was applied to the participants of the experimental group, which get eight general phases [12]:

a. Presentation of global stimulus. b. Subdivision of initial global stimulus into meaningful parts.

c. Decoding of the previous parts.

d. Concept understanding.

e. Learning links (networks) about the concept.

f. Experiential practices through multisensory processes (psychomotricity, music, video).

g. Perceptual- cognitive reconstruction of the contextual stimulus.

h. Recover information from the learned links.

\section{Results}

\section{The sample}

A total of 27 participants join in this study, 9 students are diagnosed with ASD1, 9 with ASD2 and 9 with ASD3; 6 students are 4-6 years old, 7 are 7-9 years old, 7 are 10-12 years old, and 7 are 13-15 years; 23 are men and 4 females.

Sample was distributed in two groups: $1 \mathrm{EG}(\mathrm{n}=15)$ and $1 \mathrm{CG}$ $(\mathrm{n}=15)$, that can be seen in Table 2 . 
Table 2: Participants' distribution $(\mathrm{N}=27)$.

\begin{tabular}{|c|c|c|c|c|c|c|c|c|c|}
\hline \multirow{2}{*}{ GROUP } & \multicolumn{3}{|c|}{ DIAGNOSIS } & \multicolumn{3}{c|}{ AGE } & \multicolumn{2}{c|}{ SEX } \\
\cline { 2 - 12 } & TEA1 & TEA2 & TEA3 & $\mathbf{4 - 6}$ & $\mathbf{7 - 9}$ & $\mathbf{1 0 - 1 2}$ & $\mathbf{1 3 - 1 5}$ & MEN & FEMALE \\
\hline EG & 4 & 5 & 5 & 2 & 2 & 5 & 5 & 12 & 2 \\
\hline CG & 5 & 4 & 4 & 3 & 3 & 4 & 3 & 11 & 2 \\
\hline
\end{tabular}

\section{Comparative analysis intergroup}

In Table 3 can be observed the multivariate test for the 3 successive measurements. Results found significant changes throughout research study ( 9 months), concluding that there're meaningful differences for the variable "networks" (value $=.92, \mathrm{~F}=$ 141.18 , error $=24.00$, sig $=.00$ ). Likewise, the data of 3 measures to the variable "networks" in relation to the variable "group" point that there're significant differences between participants of the experimental group and participants of the control group (value= $.73, \mathrm{~F}=34.00$, error $=24.00$, sig= .00 ). However, the comparative Table 3: Multivariate Tests(b). effects test between groups of Mauchly (Table 4) doesn't allow refuse the equality hypothesis of means with about the "networks" variable evolution, nor in relationship to the variable "group" (sig = .20), so it's necessary to complete analysis with the Within-Subjects Effects Tests (Table 5). Indeed, in the Within Subjects Design Test of Table 6, data of previous multivariate analysis are confirmed, in which significant critical levels are found, both, for the variable "networks1-2-3" (sig.= .00, F= 148.15), as well as significant differences in relation to variable "group" ( $\operatorname{sig}=.00, \mathrm{~F}=40.38$, mean square of error $=.205$ ).

\begin{tabular}{|c|c|c|c|c|c|}
\hline Effect & & Value & F & Hypothesis df & Error df \\
\hline networks & Pillai's Trace & .92 & $141.18(\mathrm{a})$ & 2.00 & 24.00 \\
\hline & Wilks' Lambda & .07 & $141.18(\mathrm{a})$ & 2.00 & 24.00 \\
\hline & Hotelling's Trace & 11.76 & $141.18(\mathrm{a})$ & 2.00 & 24.00 \\
\hline & Roy's Largest Root & 11.76 & $141.18(\mathrm{a})$ & 2.00 & 24.00 \\
\hline & Pillai's Trace & .73 & $34.00(\mathrm{a})$ & 2.00 & 24.00 \\
\hline & Wilks' Lambda & .26 & $34.00(\mathrm{a})$ & 2.00 & 2.00 \\
\hline & Hotelling's Trace & 2.83 & $34.00(\mathrm{a})$ & 24.00 & \\
\hline
\end{tabular}

a) Exact statistic

b) Design: Intercept+ GROUP.

Within Subjects Design: networks.

Table 4: Mauchly's Test of Sphericity(b).

\begin{tabular}{|c|c|c|c|c|c|c|c|}
\hline $\begin{array}{c}\text { Within Subjects } \\
\text { Effect }\end{array}$ & Mauchly's W & Approx. Chi-Square & df & Sig. & \multicolumn{2}{|c|}{ Epsilon(a) } \\
\hline & & & & & $\begin{array}{c}\text { Greenhouse- } \\
\text { Geisser }\end{array}$ & Huynh-Feldt & Lower-bound \\
\hline networks &, 87 & 3,16 & 2 &, 20 &, 89 &, 99 \\
\hline
\end{tabular}

a) May be used to adjust the degrees of freedom for the averaged tests of significance. Corrected tests are displayed in the Tests of Within-Subjects Effects table.

b) Design: Intercept+GROUP.

Table 5: Tests of Within-Subjects Effects.

\begin{tabular}{|c|c|c|c|c|c|}
\hline \multirow{2}{*}{ Source } & & $\begin{array}{c}\text { Type III Sum of } \\
\text { Squares }\end{array}$ & df & Mean Square & 30.38 \\
\hline \multirow{2}{*}{ networks } & $\begin{array}{c}\text { Sphericity } \\
\text { Assumed }\end{array}$ & 60.76 & 2 & 0 \\
\hline & $\begin{array}{c}\text { Greenhouse- } \\
\text { Geisser }\end{array}$ & 60.76 & 1.78 & 34.13 \\
\hline & Huynh-Feldt & 60.76 & 1.98 & 30.63 & 0 \\
\hline & Lower-bound & 60.76 & 1 & 0.15 \\
\hline
\end{tabular}

Citation: Manuel O R. Comparative Analysis of Development Program of Concepts and Categories Through Cognitive Perceptive Networks in 


\begin{tabular}{|c|c|c|c|c|c|c|}
\hline networks* GROUP & $\begin{array}{l}\text { Sphericity } \\
\text { Assumed }\end{array}$ & 16.56 & 2 & 8.28 & 40.38 & 0 \\
\hline & $\begin{array}{l}\text { Greenhouse- } \\
\text { Geisser }\end{array}$ & 16.56 & 1.78 & 9.3 & 40.38 & 0 \\
\hline & Huynh-Feldt & 16.56 & 1.98 & 8.35 & 40.38 & 0 \\
\hline & Lower-bound & 16.56 & 1 & 16.56 & 40.38 & 0 \\
\hline \multirow[t]{4}{*}{ Error(networks) } & $\begin{array}{c}\text { Sphericity } \\
\text { Assumed }\end{array}$ & 10.25 & 50 & 0.2 & & \\
\hline & $\begin{array}{l}\text { Greenhouse- } \\
\text { Geisser }\end{array}$ & 10.25 & 44.49 & 0.23 & & \\
\hline & Huynh-Feldt & 10.25 & 49.58 & 0.2 & & \\
\hline & Lower-bound & 10.25 & 25 & 0.41 & & \\
\hline
\end{tabular}

Table 6: Tests of Within-Subjects Contrasts.

\begin{tabular}{|c|c|c|c|c|c|c|}
\hline Source & factor1 & Type III Sum of Squares & df & Mean Square & F & Sig. \\
\hline networks & Linear & 59.85 & 1 & 59.85 & 242.20 & .00 \\
\hline & Quadratic & .90 & 1 & .90 & 5.53 & .02 \\
\hline networks* GROUP & Linear & 16.52 & 1 & 16.52 & 66.86 & .00 \\
\hline & Quadratic & .03 & 25 & .03 & .22 & .63 \\
\hline Error (networks) & Linear & 6.17 & 25 & .16 & & \\
\hline & Quadratic & 4.07 & & \\
\hline
\end{tabular}

Data summary of ANOVA is estimated that the evolution of the variable "networks1-2-3" evidence significant differences throughout its evolution ( $\mathrm{sig}=.00$, linear $\mathrm{F}=242.20$ ) and, also, this evolution is significantly different depending on the participants group type $(\operatorname{sig}=.00$, linear $\mathrm{F}=66.86)$. Indeed, changes found in variable "networks" related to the group type can be seen in Table 7. It looks like experimental group develop from 2.00 in "networks1" to 3.79 in "networks2" and 5.21 in "netswork3" (difference= 3.21 p.). Control group data is slightly lower, since develop from 2.38 in "networks1" to 3.15 in "networks2" and to 3.38 in "networks3"

Table 7: Group Statistics. (difference $=1$ p.), being total difference between the EG and CG of $2.21 \mathrm{p}$. The independent samples t- test for equality of means (Table 8) confirms the differences found in the 3 successive measures in the variable "networks" in relation to variable "group". This test points out that the differences in first measure aren't significant contrasts ("nextwork1" = .18), second measure also doesn't find significant different levels: "networks2" (sig = .07), nevertheless, third measure: "networks3", show significant differences between the experimental group participants and the peers of the control group (sig=.00).

\begin{tabular}{|c|c|c|c|c|c|}
\hline & GROUP & N & Mean & Std. Deviation & Std. Error Mean \\
\hline Networks1 & EG & 14 & 2.00 & .67 & .18 \\
\hline & CG & 13 & 2.38 & .76 & .21 \\
\hline Networks2 & EG & 14 & 3.79 & .80 & .21 \\
\hline Networks3 & CG & 13 & 3.15 & .80 & .21 \\
\hline & EG & 14 & 5.21 & .76 & .21 \\
\hline
\end{tabular}

Table 8: Independent Samples Test.

\begin{tabular}{|c|c|c|c|c|c|c|c|c|c|c|}
\hline & \multicolumn{3}{|c|}{$\begin{array}{c}\text { Levene's Test for Equality of } \\
\text { Variances }\end{array}$} & \multicolumn{7}{|c|}{ t-test for Equality of Means } \\
\hline & & \multirow[t]{2}{*}{$\mathbf{F}$} & \multirow[t]{2}{*}{ Sig. } & \multirow[t]{2}{*}{$\mathbf{t}$} & \multirow[t]{2}{*}{ df } & \multirow[t]{2}{*}{$\begin{array}{c}\text { Sig. } \\
\text { (2-tailed) }\end{array}$} & \multirow[t]{2}{*}{$\begin{array}{c}\text { Mean } \\
\text { Difference }\end{array}$} & \multirow[t]{2}{*}{$\begin{array}{l}\text { Std. Error } \\
\text { Difference }\end{array}$} & \multicolumn{2}{|c|}{$\begin{array}{l}95 \% \text { Confidence } \\
\text { Interval of the } \\
\text { Difference }\end{array}$} \\
\hline & & & & & & & & & Lower & Upper \\
\hline \multirow[t]{2}{*}{ Nextworks1 } & $\begin{array}{l}\text { Equal variances } \\
\text { assumed }\end{array}$ & 1.92 & 0.17 & -1.38 & 25 & 0.18 & -0.38 & 0.27 & -0.95 & 0.18 \\
\hline & $\begin{array}{l}\text { Equal variances not } \\
\text { assumed }\end{array}$ & & & -1.37 & 24.05 & 0.18 & -0.38 & 0.28 & -0.96 & 0.19 \\
\hline
\end{tabular}




\begin{tabular}{|l|c|c|c|c|c|c|c|c|c|c|}
\hline Nextworks2 & $\begin{array}{c}\text { Equal variances } \\
\text { assumed }\end{array}$ & 0.33 & 0.56 & 1.83 & 25 & 0.07 & 0.63 & 0.34 & -0.07 & 1.34 \\
\hline & $\begin{array}{c}\text { Equal variances not } \\
\text { assumed }\end{array}$ & & 1.81 & 23.17 & 0.08 & 0.63 & 0.34 & -0.08 & 1.35 \\
\hline Nextworks3 & $\begin{array}{c}\text { Equal variances } \\
\text { assumed }\end{array}$ & 0 & 0.94 & 6.04 & 25 & 0 & 1.83 & 0.3 & 1.2 & 2.45 \\
\hline & $\begin{array}{c}\text { Equal variances not } \\
\text { assumed }\end{array}$ & 6.05 & 24.97 & 0 & 1.83 & 0.3 & 1.2 & 2.45 \\
\hline
\end{tabular}

\section{Conclusion}

In this research the effectiveness of the applied program could be contrasted, since students of the experimental group have improved significantly, compared to their peers of control group. The improvements found at a comparative level refer to two fundamental aspects:

i. To the levels of sensoryintegrationand gestaltorganization, measured through the Frostig test, operationalized in variable "frostig".

ii. To semantic integration and conceptual understanding processes, evaluated throughout improving the understanding of a text adapted to age and curricular competence, operationalized in variable "text".

The data found to variable calculated: "nextworks", which unifies both variables: "frostig" and "text", allows conclude that the experimental group students have improved sensibly compared to control group peers in sensory perception integration and in processes of semantic coding. Conclusions confirm existence of a neural interrelation between the basic psychological processes during activity of the cognitive development, then specific programs are necessary that facilitate creation of the networks and semantic links, related with the conceptual information and the previously learned concepts. Likewise, it's essential to forward creation of conceptual categories in semantic memory along the learning process, which globalizes sensory information perceived. Indeed, CG participants also evolved in conceptual creation, but they didn't significantly as the EG participants, who improved more than their peers of control group, due to application of this program.

\section{Discussion}

Indicate that processing of information depends on global perception of stimuli, understanding and semantic analysis, but in people with ASD this process doesn't occur spontaneously, owing to limited perception and to deficits in construction of interrelated links between the new information and previous contents. Several studies of Cognitive Psychology [13-17] conclude that cognitive functioning is an interrelated systemic process, in which the different basic psychological processes don't act alone, but that these processes: perception, attention, emotion, motivation and memory interact dynamically during human cognitive action and any component that impedes the functioning of a process, thus, all processes will be affected, not only at the sensory perception, but also in the coding processes. This systemic interaction is developed through intersection of inherent thought process, which is linked to a semantic- pragmatic process about its own functioning dynamics, through which it's understood and, finally, encoded. In this sense, the analysis and codification of the perceived reality configure a peculiar mode of information processing in people with ASD that influences its global processing mode. There're previous studies that show the mutual influence of the cognitive process performing how a continuous process that goes from the perception of internal or external stimulus to execution of action itself, therefore, there's a great number of researches have like aim to ease specific perceptual- cognitive development programs for individuals with ASD [18-22].

\section{Study Limitations}

This study is limited by small number of participants because working with people with specific needs is always limited to small samples, so new tests are necessary to corroborate these results.

\section{Acknowledgment}

I would like to express my gratitude to the families and professionals of the Association of Families of People with Social Communication Disorders in Ourense, as well as to families and professionals of the educational centers who have participated in this study.

\section{References}

1. (2013) Diagnostic and statistical manual of mental disorders DSM-5 $®$ ( $5^{\text {th }}$ edn,). Washington: American Psychiatric Association.

2. Napoli E, Russo S, Casula L, Alesi V, Amendola FA, et al. (2018) Array CGH analysis in a cohort of phenotypically well characterized individuals with Essential autism spectrum disorders. Journal of Autism and Developmental Disorders 48(2): 442-449.

3. Lieberman DA (2012) Human learning and memory. Cambridge: University Press.

4. Whyte EM, Behrmann M, Minshew NJ, Garcia NV, Scherf KS (2016) Animal, but not human, faces engage the distributed face network in adolescents with autism. Developmental Science 19(2): 306- 317.

5. Ibrahim GM, Morgan BR, Vogan VM, Leung RC, Anagnostou E, et al. (2016) Mapping the network of neuropsychological impairment in children with autism spectrum disorder: a graph theoretical analysis. Journal of Autism and Developmental Disorders 46(12): 3770- 3777.

6. Jaime M, McMahon CM, Davidson BC, Newell LC, Mundy PC, et al. (2016) Brief report: reduced temporal-central EEG alpha coherence during joint attention perception in adolescents with autism spectrum disorder. Journal of Autism and Developmental Disorders 46(4): 1477-1489.

7. Frith U (2003) Autism: explaining the enigma (2 $2^{\text {nd }}$ edn.), Oxford: Blackwell, USA. 
8. Booth RD, Happe FG (2018) Evidence of reduced global processing in autism spectrum disorder. Journal of Autism and Developmental Disorders 48(4): 1397-1408.

9. Mercado E, Church BA (2016) Brief report: simulations suggest heterogeneous category learning and generalization in children with autism Is a result of idiosyncratic perceptual transformations 46(8): 2806-2812.

10. Callenmark B, Kjellin L, Rönnqvist L, Bölte S (2014) Explicit versus implicit social cognition testing in autism spectrum disorder. Autism: The International Journal of Research and Practice 18(6): 684-693.

11. Koegel RL, Bradshaw JL, Ashbaugh K, Koegel LK (2014) Improving question asking initiations in Young children with autism using pivotal response treatment. Journal of Autism and Developmental Disorders 44(4): 816- 827.

12. Ojea M (2018) RELATEA PROGRAM. Development of conceptual categories in students with autism spectrum disorders. Madrid: Pirámide.

13. Brandwein AB, Foxe JJ, Butler JS, Frey HP, Bates JC, et al. (2015) Neurophysiological indices of atypical auditory processing and multisensory integration are associated with symptom severity in autism. Journal of Autism and Developmental Disorders 45(1): 230-244.

14. Elison JT, Wolff JH, Debra C, Paterson SJ, Gu H, et al. (2013) Frotolimbic neural circuitry at 6 months predicts individual differences in joint attention at 9 months. Developmental Science 16(2): 186-197.

15. Greimel E, Nehrkorn B, Fink GR, Kukolja J, Kohls G, Muller K, et al. (2012) Neural mechanisms of encoding social and no social context information in autism spectrum disorder. Neuropsychology 50(14): 3440- 3449
To Submit Your Article Click Here: Submit Article

DOI: $10.32474 /$ SJPBS.2018.01.000101
16. Kimhi Y, Shoam Kugelmas D, Agam G, Ben Moshe I, Bauminger Zviely $N$ (2014) Theory of mind and executive function in preschoolers with typical development versus intellectually able preschoolers with autism spectrum disorder. Journal of Autism and Developmental Disorders 44(9): 2341-2354.

17. Voos AC, Pelphrey KA, Tirrell J, Bolling DZ, Vander WB, et al. (2013) Neural mechanisms of improvements in social motivation after pivotal response treatment: two case studies. Journal of Autism and Developmental Disorders 43(1): 1- 10.

18. Cheung PP, Siu AM, Brown T, Yu M (2018) A Social-cognitive intervention program for adolescents with autism: a pilot study. Journal of Occupational Therapy, Schools \& Early Intervention 11(1): 37-48.

19. Verdier de K, Fernell E, Ek U (2018) Challenges and successful pedagogical strategies: experiences from six swedish students with blindness and autism in different school settings. Journal of Autism and Developmental Disorders 48(2): 520- 532.

20. Kuder SJ, Accardo A (2018) What works for college students with autism spectrum disorder? Journal of Autism and Developmental Disorders 48(3): 722-731.

21. Spaniol MM, Shalev L, Kossyvaki L, Mevorach C (2018) Attention training in autism as a potential approach to improving academic performance: a school-based pilot study. Journal of Autism and Developmental Disorders 48(2): 592- 610.

22. Martzoukou M, Papadopoulou D, Kosmidis M (2017) The comprehension of syntactic and affective prosody by adults with autism spectrum disorder without accompanying cognitive deficits. Journal of Psycholinguistic Research 46(6): 1573- 1595.

\begin{tabular}{|l|l|}
\hline SJPBS & $\begin{array}{c}\text { Scholarly Journal of Psychology } \\
\text { and Behavioral Sciences }\end{array}$ \\
Assets of Publishing with us
\end{tabular}

